\title{
A New Bonding Process for Ceramics
}

\section{REACTION WELDING WITH A GOLD FILLER}

\section{H. J. de Bruin}

The Flinders University of South Australia

\author{
A. F. Moodie and C. E. Warble \\ C.S.I.R.O., Division of Chemical Physics, Clayton, Victoria, Australia
}

Solid state reactions occurring at the interface between ceramic oxides and gold form the basis of a new means of obtaining strong and vacuum-tight joints in a wide range of synthetic ceramics. Industrial applications of the process are now being evaluated.

A wide range of synthetic ceramics, each designed to meet specific requirements, is now available to the electrical and electronic engineer for use in vacuum tube technology, semiconductor devices, high temperature fuel cells, nuclear engineering and other sophisticated equipment. In some cases, however, their applications are limited by the difficulty of joining them to other ceramic bodies to form composite structures. The techniques presently available for this purpose involve a type of brazing operation in which a metal alloy or a glass is heated to above its melting point, the liquid phase then wetting both surfaces. Unfortunately the wetting angles between most alloys and ceramics are substantially larger than $90^{\circ}$ and wetting is most difficult to achieve.

A collaborative research programme initiated by the School of Physical Sciences of Flinders University and the Commonwealth Scientific and Industrial Research Organisation has now led to the development of a new method for bonding ceramics, using thin noble metal foils $(1,2,3)$. In this process, in contrast to conventional brazing and welding, no melting is involved.

The mechanism of the bonding process has been shown to result from a chemical reaction taking place at the interface between noble metals and ceramic oxides such as magnesia, alumina, stabilised zirconia, beryllia, thoria, and also quartz and silicate glasses. A striking fact, established by scanning electron microscopy and electron probe microanalysis, is the absence of metal diffusion into the ceranic as shown in Fig. 1 .

The process itself consists simply of heating both materials to a specific temperature below the melting point of either component in any compatible atmosphere - usually air or vacuum - and under slight pressure to improve contact. Heating, which can be by any appropriate means such as an induction heater or muffle furnace, ranges from a few minutes to several hours.
Fig. 1 Energy filtered scanning electron micrographs of reaction-welded composites. The absence of metal diffusion into the ceramic in a nohle metal hond is shown in (a), which is a micrograph of an $\mathrm{Al}_{2} \mathrm{O}_{3} / \mathrm{Au} / \mathrm{Al}_{2} \mathrm{O}_{3}$ composite. For comparison a nickelbonded composite with an obvious diffusion region $D$ is shown in (b)

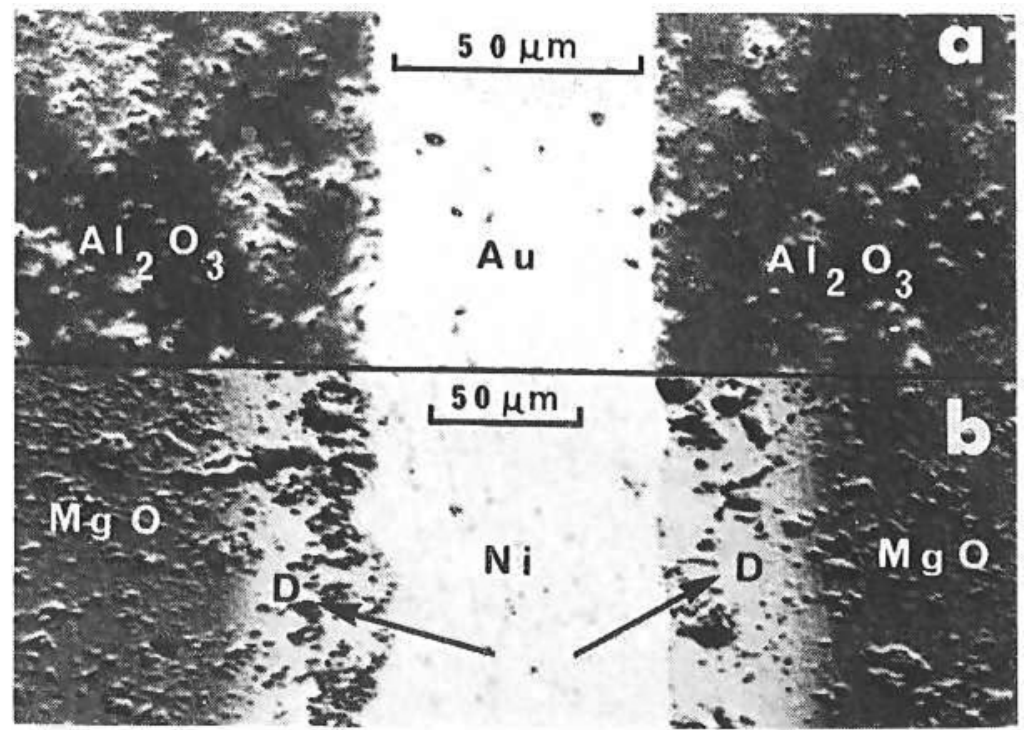


Fig. 2 A group of miscellaneous ceramic com. ponents joined by the new reaction welding process, using gold as the jointing medium
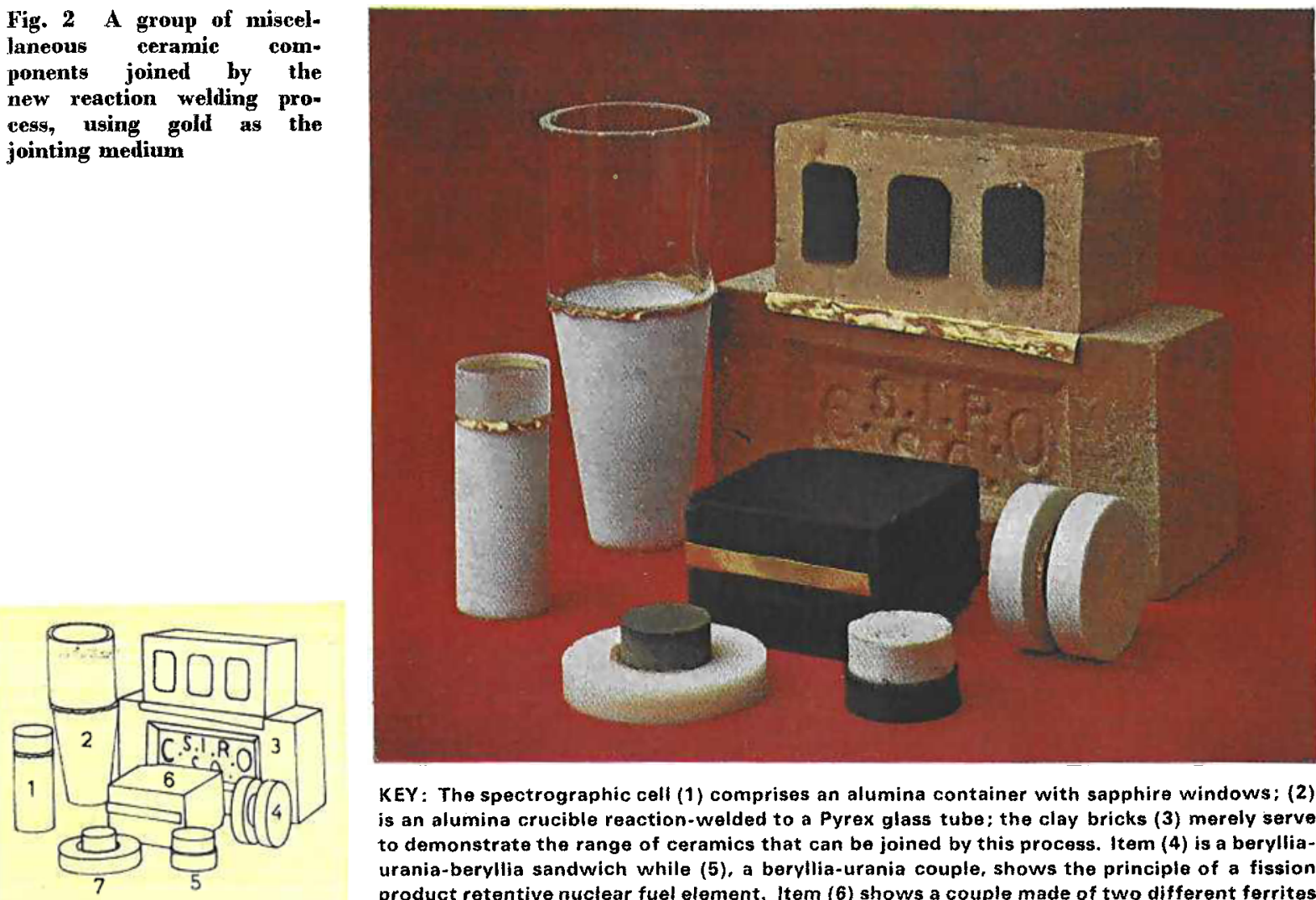

KEY: The spectrographic cell (1) comprises an alumina container with sapphire windows; (2) is an alumina crucible reaction-welded to a Pyrex glass tube; the clay bricks (3) merely serve to demonstrate the range of ceramics that can be joined by this process. Item (4) is a berylliaurania-beryllia sandwich while (5), a beryllia-urania couple, shows the principle of a fission product retentive nuclear fuel element. Item (6) shows a couple made of two different ferrites and (7) a nicke! oxide-alumina couple

Vacuum-tight bonds are produced in this way, and their ultimate shear strengths have been found to exceed those of the ceramics being joined.

The illustrations show several examples of reactionwelded ceramics, in each case joined with gold foil about $50 \mu \mathrm{m}$ in thickness. Gold as a filler is often preferred to other noble metals such as platinum or palladium when the particular application does not demand temperatures above $1000^{\circ} \mathrm{C}$. Its high ductility, even in the presence of minor impurities that are inevitably introduced, relieves thermal stresses when materials of greatly differing expansion characteristics are bonded. There is substantial evidence (2) to show that the stresses at the metal/ ceramic interface are negligible even on quenching from $1000^{\circ} \mathrm{C}$ to approximately $-100^{\circ} \mathrm{C}$ in one second. However, thermal expansion coefficients of ceramics can vary by a factor of ten or more.

Gold is chemically compatible with almost all oxides even near its melting point. This makes it attractive as a welding filler for equipment used under corrosive conditions. The spectrographic cell

Fig. 3 A close-np view of the bond in the spectrographic cell made from an alumina container with sapphire windows

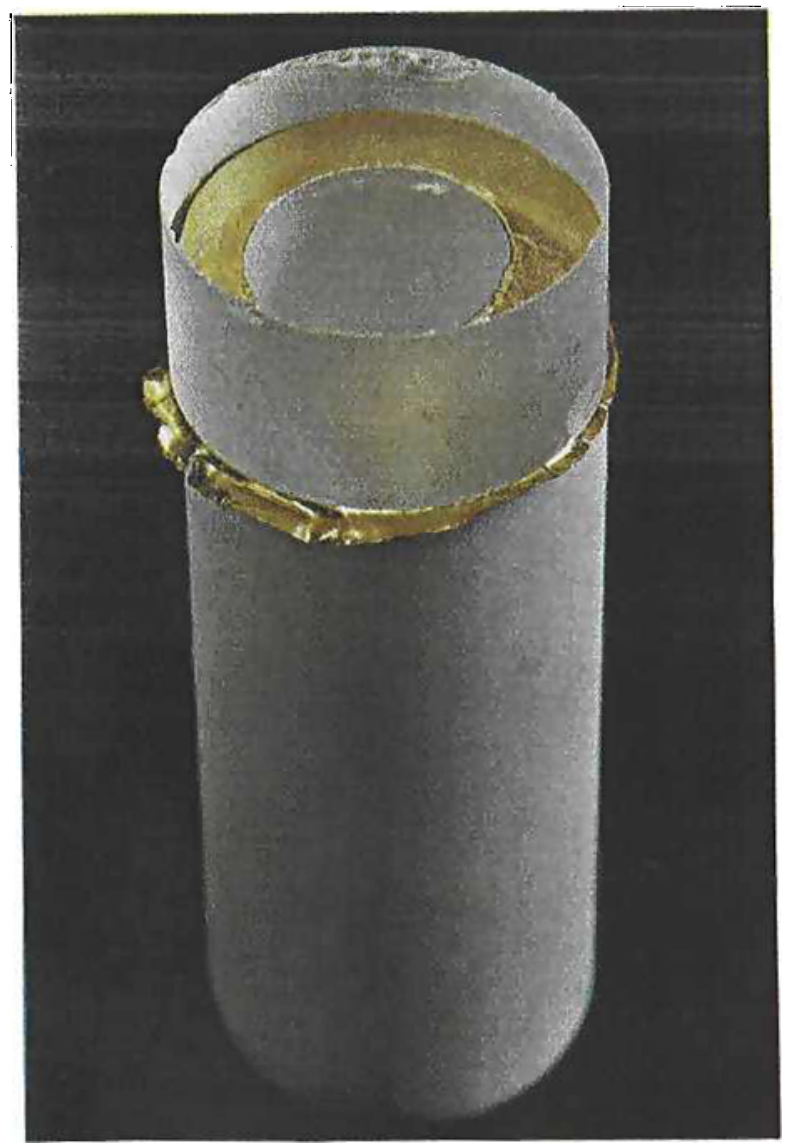




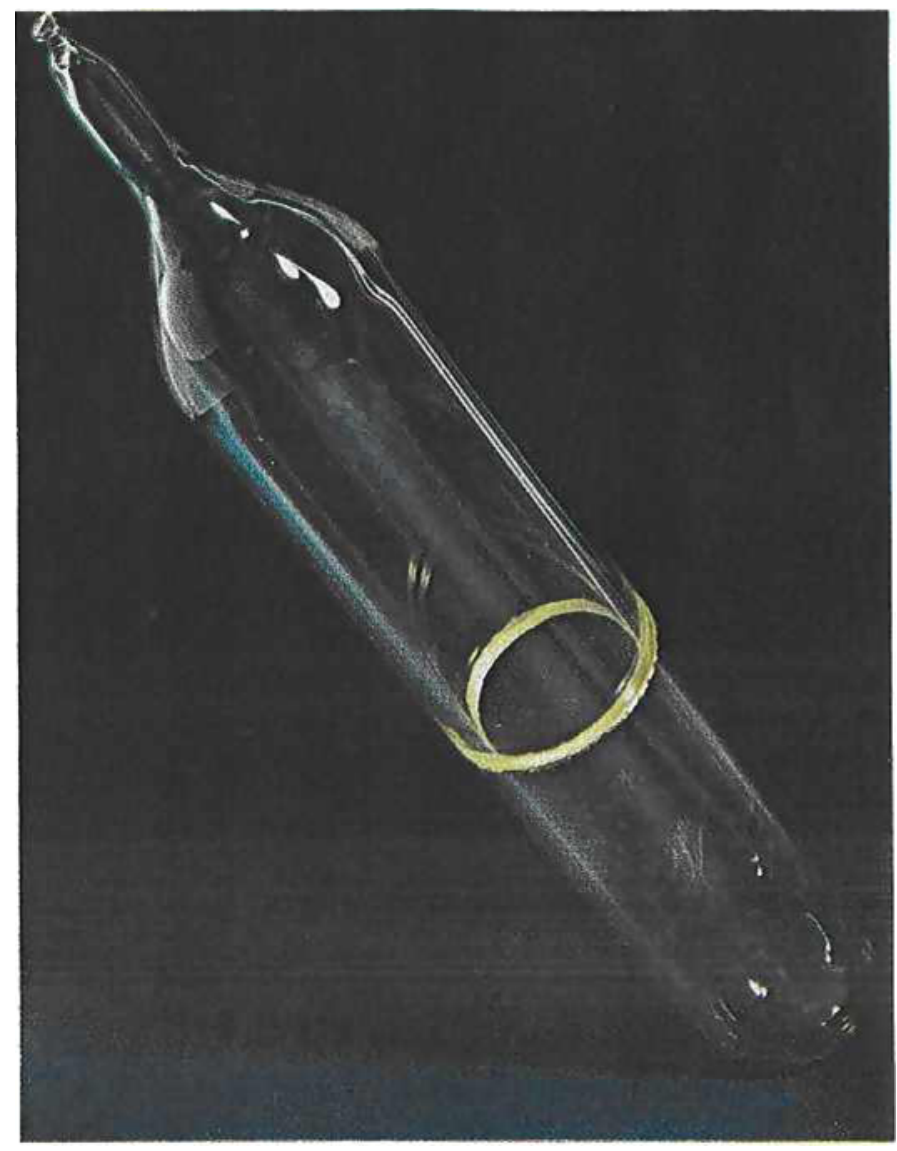

Fig. 4 An example of a vacuum-tight seal made by reaction welding. This Pyrex/gold/Pyrex test assembly has been maintained for eighteen months under a vacuum of $10^{-6}$ torr

The use of another metal filler in this case would certainly be more appropriate, but the couple shows the scope of the method.

Perhaps the most important area of potential applications is electronic technology. The possibility of making perfect contact between electrical conductors (metals) and insulators (ceramics) is very attractive. This can be done by the reactionwelding process. Non-conducting and high frequency magnetic oxides (ferrites), piezoelectrics, anti-ferroelectrics, and many other special oxides can be reaction-welded. Fig. 2 shows a couple of two different ferrites (number 6).

The compatibility with most oxides is also shown in the welded nickel oxide/ alumina couple in Fig. 2 (number 7 ). These oxides in contact with each other form a range of spinels. Reactions such as these

in Fig. 2 (number 1 in the layout diagram) consists of an alumina container with sapphire windows reaction-welded with gold. A close up of the bond is shown in Fig. 3.

Number 2 in Fig. 2 is an alumina crucible reaction welded to a Pyrex glass tube for incorporation in glass equipment as used in high temperature research. The crucible can be simply removed on melting the gold, for instance, by means of a brief burst of power from an induction coil.

It is scarcely suggested that gold should replace mortar in the building industry, but the specimen clay bricks in Fig. 2 (number 3 ) reaction welded with gold, provide some indication of the range of ceramics that can be bonded by this simple process. Classical ceramics, such as all-clay products for structural and ornamental purposes, so-called superrefractory high purity oxides, as well as many silicates including the glasses fall in this range.

Gold is not an attractive nuclear material. However, the beryllia/urania/beryllia sandwich (number 4 in Fig. 2) and the beryllia/urania couple (number 5 in Fig. 2) reaction welded with gold foil, shows the principle of a fission product retentive nuclear fuel element. This particular fuel-moderator combination has long been under consideration as a heterogeneous fuel element for advanced gas-cooled nuclear reactors. occur widely and prevent the formation of stable bonds between differing oxides by hot pressing, or cold pressing and sintering. The gold foil prevents contact between incompatible oxides and yet bonds both of them very strongly.

Gold is an ideal filler for the making of vacuum tight seals. An example is shown in Fig. 4. This Pyrex/gold/Pyrex test assembly has been maintained for eighteen months under a vacuum of $10^{-6}$ torr $\left(10^{-4} \mathrm{~N} / \mathrm{m}^{2}\right)$.

These are a few examples illustrating the scope of the new reaction welding process and the important place that gold occupies in this new technique. All are 'unfinished' because the use of finished products displaying specific industrial applications is precluded by the present stage of negotiations with the industries concerned. The exact nature of the bond between ceramic oxides and the noble metals is currently under investigation by means of electron microscopy, electron probe microanalysis, radiochemical and several other techniques.

\section{References}

1 H. I. de Bruin, A. F. Moodie and C. E. Warble, F. Australian Ceram. Soc., 1971, 7, (2), 57

2 H. J. de Bruin, A. F. Moodie and C. E. Warble, $\mathcal{F}$. Mater. Sci. (in press)

3 Australian Patent Appl.25585/71 